\title{
Utilization of dental services among low and middle income pregnant, post-partum and six-month post-partum women
}

\author{
Jagan Kumar Baskaradoss ${ }^{1 *}$ and Amrita Geevarghese ${ }^{2}$
}

\begin{abstract}
Background: This study aims to explore the difference in the utilization pattern of dental services among pregnant, post-partum and six-month post-partum women.

Methods: This cross-sectional questionnaire survey was performed at two maternity and child care hospitals in India that primarily cater to middle and low income communities. Data were collected from 3 groups: 1) pregnant women in their first trimester; 2) post-partum women ( $<48 \mathrm{~h}$ after delivery); and 3) six-month post-partum women. The primary outcome of interest was dental service utilization during pregnancy. Self-perceived oral health (SPOH) was calculated based on the four global dimensions- knowledge, function, quality of life and social. Multiple logistic regression analysis was carried out to assess the effect of each independent variable after adjustment for the effect of all other variables in the model.
\end{abstract}

Results: Responses of 450 (150 pregnant, 150 post-partum and 150 six-month post-partum) women were analyzed (response rate $=72 \%$ ). Significant differences in the dental attendance pattern was observed between the study groups $(p<0.01)$. Dental attendance among pregnant and six-month post-partum women were 60 and 75\%, respectively, however, only about $15 \%$ of the post-partum women reported to have sought dental care within the 6 months prior to the study. Post-partum women had the highest SPOH scores, indicating poor self-perceived oral health, followed by pregnant and then six-month post-partum women, which was statistically significant $(p<0.05)$. A significantly higher percentage of post-partum women reported to have poor oral and general health, as compared to both, pregnant and six-month post-partum women $(p<0.01)$. Higher percentage of women reporting 'good' oral and general health had sought dental care compared with others $(p<0.01)$. After adjusting for all the other variables in the model, women with lower levels of education $\left(\mathrm{OR}^{\mathrm{a}}=1.42 ; 95 \% \mathrm{Cl}: 1.01-2.00\right)$, women with poor self-perceived oral health $\left(\mathrm{OR}^{\mathrm{a}}=1.08 ; 95 \% \mathrm{Cl}: 1.02-1.14\right)$ and post-partum women $\left(\mathrm{OR}^{\mathrm{a}}=0.15 ; 95 \% \mathrm{Cl}\right.$ : $0.09-$ 0.24) were found to be less likely to seek regular dental care.

Conclusion: Pattern of dental service utilization among women in this population varied according to their pregnancy status, level of education and self-perceived oral health.

\footnotetext{
* Correspondence: drjaganb@gmail.com

${ }^{1}$ Division of Dental Public Health, Department of Developmental and

Preventive Sciences, Faculty of Dentistry, Kuwait University, 13110 Kuwait

City, Kuwait

Full list of author information is available at the end of the article
}

(C) The Author(s). 2020 Open Access This article is licensed under a Creative Commons Attribution 4.0 International License, which permits use, sharing, adaptation, distribution and reproduction in any medium or format, as long as you give appropriate credit to the original author(s) and the source, provide a link to the Creative Commons licence, and indicate if changes were made. The images or other third party material in this article are included in the article's Creative Commons licence, unless indicated otherwise in a credit line to the material. If material is not included in the article's Creative Commons licence and your intended use is not permitted by statutory regulation or exceeds the permitted use, you will need to obtain permission directly from the copyright holder. To view a copy of this licence, visit http://creativecommons.org/licenses/by/4.0/ The Creative Commons Public Domain Dedication waiver (http://creativecommons.org/publicdomain/zero/1.0/) applies to the data made available in this article, unless otherwise stated in a credit line to the data. 


\section{Background}

Pregnancy is associated with a number of psychological and hormonal changes in women [1]. An increase in the secretion of hormones like estrogen and progesterone leads to gingival inflammation [2]. Maintaining good oral health before, during and after pregnancy is important not only for the mother but also for the health of the infant. Studies have shown that maternal periodontitis can lead to preterm low birth weight babies [3-5]. Poor maternal oral health during pregnancy has been associated with early childhood caries and also long term systemic disorders for the newborn [6]. From a psychological perspective, poor periodontal health is associated with poor oral health related quality of life among pregnant women [7].

The oral health of pregnant women is influenced by various socio-cultural factors including education and socio-economic status [8]. Limited access to oral health resources, medical conditions that influence oral health, and limited knowledge of the relationship between oral and general health might be the reason for this association [9].

The dental need could either be 'perceived need', which takes into account the individuals' self-perception of their oral health or 'normative need', which is the professionally determined need, based on the subjects' clinical findings [10]. Relying solely on normative methods without integrating the individual's perception of dental health may lead to overestimation of dental care needs [11]. Along with the concept of need, several other factors like patient's socio-demographic characteristics and availability of dentists also influence the dental service utilization. Andersen's [12] behavioral model of health services use has been widely used in dentistry to explain the predictors of dental service utilization (Fig. 1).

Most dental procedures can be performed safely in pregnant women [13]. Several organizations have put forth the recommendation that pregnant women should undergo routine dental prophylaxis during pregnancy. The American Academy of Pediatric Dentistry recommends that all women should receive a comprehensive oral health evaluation and risk assessment during pregnancy [14]. The American Academy of Periodontology also recommends that pregnant women with periodontitis receive treatment during pregnancy [15]. The American College of Obstetricians and Gynecologists recommend that women should routinely be counseled about the maintenance of good oral health habits throughout their lives as well as the safety and importance of oral health care during pregnancy [16]. However, pregnant women often defer necessary dental treatment

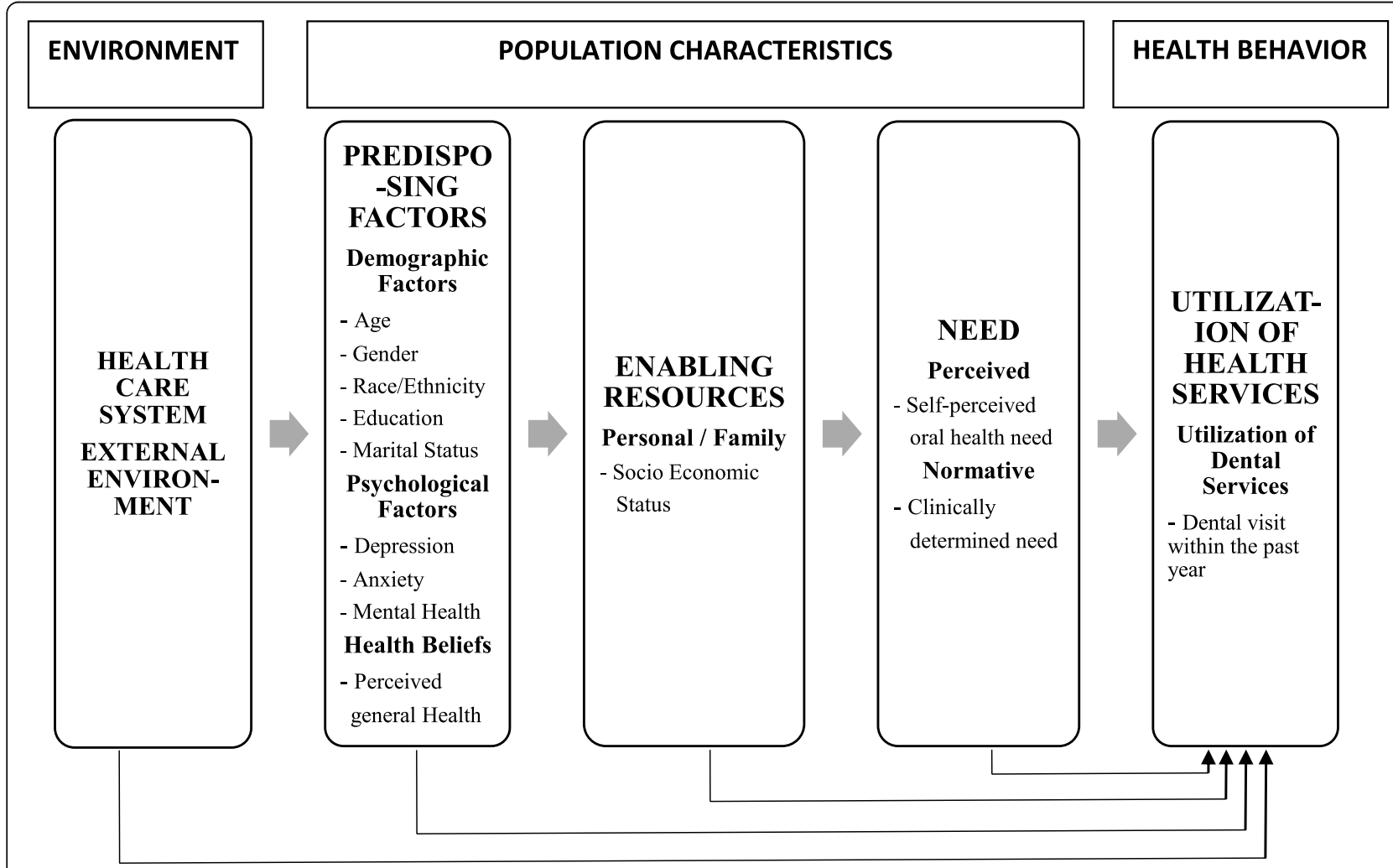

Fig. 1 Andersen's emerging behavioral model of health services use 
until after delivery [15]. Several factors have been reported in the literature that deter women from seeking dental care during pregnancy, such as socio-economic and socio-cultural factors, lack of public awareness of the importance of oral health and concerns for fetal safety during dental treatment [17].

Several studies have reported on the oral health practices among pregnant women $[18,19]$. However, minimal information is available on the utilization of dental services among low and middle income women. The aim of this study was to explore the difference in the utilization pattern of dental services among low and middle income pregnant, post-partum and six-month post-partum women.

\section{Methods}

This cross-sectional questionnaire survey was performed at two of the largest maternal and child care hospitals (Women and Child Hospital and Sri Avittom Tirunal Hospital) in the State of Kerala, India. Written consent was obtained from the concerned authorities of the two hospitals. This study was conducted in accordance with the World Medical Association Declaration of Helsinki and approved by the Institutional Ethics Committee of Sree Chitra Tirunal Institute of Medical Science and Technology, Kerala, India. This study is reported based on the guidelines of strengthening the reporting of observational studies in epidemiology (STROBE) [20].

Recruitment of study participants were carried out at three different sites at these hospitals: 1) pregnant women in their first trimester-when they came for their routine antenatal consultation at the outpatient clinic of Obstetrics and Gynecology department; 2) post-partum women - after they were shifted to the post-partum labor wards (within $48 \mathrm{~h}$ ' after delivery) and 3) sixmonth post-partum women- when they bring their child for the sixth-month immunization at the immunization clinics of the respective hospitals. The sample size calculation was based on an estimation of the proportion of women utilizing dental services during pregnancy in India. Assuming $50 \%$ of women utilizing dental services [18] and assuming a difference of $20 \%$ in the utilization rates between pregnant and non-pregnant women, it was calculated that 103 subjects per group were required for achieving a power of $80 \%$ and a two-sided confidence interval (CI) of $95 \%$. This was rounded to 150 per group.

Only women between the age group of 18-35 years were invited to participate in this study. Women presenting with medically compromised conditions or those who reported to be under antibiotic therapy were excluded from the study. The investigators referred to the hospital registers to select the subjects. A structured questionnaire was administered in two parts: the first section on dental information and the second section on the utilization pattern of dental services. Sociodemographic data including age, education, religion, period of gestation, employment and socio economic status (SES) were also collected. In the study, SES was calculated based on the standard of living index (SLI) with minor modifications. This index is similar to the one used in National Family Health Survey (NFHS) II [21]. SLI was calculated on the basis of income, possession of goods, toilet facilities and the type of cooking fuel used by the respondents. Based on this score SES was divided into 'high', 'medium' and 'low' categories. The frequency of eating sugary foods was also calculated from the sum of occasions on which cakes, biscuits, confectionery, table sugar, jams and soft drinks were consumed in the previous $24 \mathrm{~h}$. The total score was then categorized as low ( $<3$ times/day), medium (3-5 times/day) and high ( $>5$ times/day). The dental beliefs of women were explored using 2 focused questions: 1) 'Do you believe that dental diseases could lead to other medical conditions?' and 2) 'Do you believe that bleeding from the gums is normal during pregnancy?'. Self-perceived oral health $(\mathrm{SPOH})$ was calculated based on the four global dimensions that was adopted from the study by Ekback et al. [22] Higher SPOH scores indicate poorer self-perceived oral health status. In this study, knowledge was assessed by three questions, function by three questions, quality of life by one question and social by two questions. Overall oral health and general health indicator was assessed by two self-rating questions 'How would you rate your oral/general health?' respectively, with the response categories: 1) Good, 2) Fair, 3) Poor. The questionnaire was pilot tested in a small group of 10 women conveniently chosen from the selected hospitals.

The primary outcome of interest was participants' dental service utilization, dichotomized as whether or not a woman reported having had a routine dental visit in the previous 6 months. Routine dental visit as a dental checkup or dental prophylaxis. Emergency dental visits are not included in this definition. The data from completed questionnaires were analyzed and the descriptive frequency tables were generated. Cross-tabulation with the chi-squared test was used to evaluate the differences between the different variables. Difference in the $\mathrm{SPOH}$ scores between the groups was analyzed using Analysis of variance (ANOVA) with Tukey's post-hoc multiple comparisons. Multiple logistic regression analysis was carried out to assess the effect of each independent variable after adjustment for the effect of all other variables in the model. $P$-value of $<0.05$ was considered significant. All statistical analyses were carried out using SPSS 17.0 software (Statistical Package for the Social Sciences for Windows ${ }^{\circ}$; SPSS Inc., Chicago, IL, USA).

\section{Results}

A total of 450 women participated in the study (response rate $=72 \%$ ). The response rate was similar across the 
Table 1 Socio-demographic and dental characteristics of the study groups stratified by their pregnancy status and utilization of dental services

\begin{tabular}{|c|c|c|c|c|c|c|c|}
\hline \multirow[t]{3}{*}{ Variables } & \multirow[b]{2}{*}{ Total } & \multicolumn{3}{|l|}{ Pregnancy Status } & \multirow{3}{*}{$\boldsymbol{P}$ value* } & \multirow{2}{*}{$\begin{array}{l}\text { Sought Dental Care (last } 6 \\
\text { months) } \\
\text { Yes }\end{array}$} & \multirow{3}{*}{$\boldsymbol{P}$ value* } \\
\hline & & $\begin{array}{l}\text { Six-month post-partum } \\
\text { women }\end{array}$ & $\begin{array}{l}\text { Pregnant } \\
\text { women }\end{array}$ & $\begin{array}{l}\text { Post-Partum } \\
\text { women }\end{array}$ & & & \\
\hline & $\begin{array}{l}450 \\
(100.0) \\
N(\%)\end{array}$ & $\begin{array}{l}150(33.3) \\
N(\%)\end{array}$ & $\begin{array}{l}150(33.3) \\
N(\%)\end{array}$ & $\begin{array}{l}150(33.3) \\
N(\%)\end{array}$ & & $\begin{array}{l}224(49.8) \\
N(\%)\end{array}$ & \\
\hline \multicolumn{8}{|l|}{ Place of Residence } \\
\hline Urban & $143(39.6)$ & $31(37.3)$ & $49(38.3)$ & $63(42.0)$ & 0.73 & $61(42.6)$ & 0.28 \\
\hline Rural & $218(60.4)$ & $52(62.7)$ & $79(61.7)$ & $87(58.0)$ & & $106(48.6)$ & \\
\hline \multicolumn{8}{|l|}{ Religion } \\
\hline Hindu & $303(67.3)$ & $98(65.3)$ & 89 (59.3) & $116(77.3)$ & 0.02 & $140(46.2)$ & 0.04 \\
\hline Christian & $86(19.1)$ & $31(20.7)$ & $37(24.7)$ & $18(12.0)$ & & $53(61.6)$ & \\
\hline Muslim & $61(13.6)$ & $21(14.0)$ & $24(16.0)$ & $16(10.7)$ & & $31(50.8)$ & \\
\hline \multicolumn{8}{|l|}{ Education } \\
\hline Primary and Secondary & $212(47.1)$ & $45(30.0)$ & $68(45.3)$ & $99(66.0)$ & $<0.01$ & $84(39.6)$ & $<0.01$ \\
\hline Higher Secondary & $146(32.4)$ & 68 (45.3.) & $40(26.7)$ & $38(25.3)$ & & $83(56.8)$ & \\
\hline Graduate and Above & $92(20.4)$ & $37(24.7)$ & $42(28.0)$ & $13(8.7)$ & & $57(61.9)$ & \\
\hline \multicolumn{8}{|l|}{ Occupation } \\
\hline Unemployed & $362(80.4)$ & $96(64.0)$ & $127(84.7)$ & $139(92.7)$ & $<0.01$ & $167(46.1)$ & $<0.01$ \\
\hline Employed & $88(19.6)$ & $54(36.0)$ & $23(15.3)$ & $11(7.3)$ & & $57(64.7)$ & \\
\hline \multicolumn{8}{|l|}{ Socio-economic status } \\
\hline Middle & $134(29.8)$ & $39(26)$ & $46(30.7)$ & $49(32.7)$ & 0.41 & $60(44.8)$ & 0.18 \\
\hline Low & $316(70.2)$ & $111(74.0)$ & $104(69.3)$ & $101(67.3)$ & & $164(51.9)$ & \\
\hline \multicolumn{8}{|c|}{ Frequency of eating sugary foods } \\
\hline$<3$ times/day & $149(33.1)$ & $64(42.7)$ & $34(22.7)$ & $51(34.0)$ & $<0.01$ & $77(51.7)$ & 0.85 \\
\hline 3-5 times/day & $211(46.9)$ & $60(40.0)$ & $77(51.3)$ & $74(49.3)$ & & $103(48.8)$ & \\
\hline$>5$ times/day & $90(20.0)$ & $26(17.3)$ & $39(26.0)$ & $25(16.7)$ & & $44(48.9)$ & \\
\hline \multicolumn{8}{|l|}{ Frequency of brushing } \\
\hline Regular (Brush > 1/day) & $240(53.3)$ & $87(58.0)$ & $85(56.7)$ & $68(45.3)$ & 0.09 & $126(52.5)$ & 0.30 \\
\hline Irregular (Brush $\leq 1 /$ day) & $210(46.7)$ & $63(42.0)$ & $65(43.3)$ & $82(54.7)$ & & $98(46.7)$ & \\
\hline \multicolumn{8}{|l|}{ Bleeding while brushing } \\
\hline No & $230(51.1)$ & $99(66.0)$ & $51(34.0)$ & $80(53.3)$ & $<0.01$ & $117(50.9)$ & 0.64 \\
\hline Yes & $220(48.9)$ & $51(34.0)$ & $99(66.0)$ & $70(46.7)$ & & $107(48.6)$ & \\
\hline \multicolumn{8}{|c|}{ Dental problems (last 6 months) } \\
\hline No & $211(46.9)$ & $82(54.7)$ & $58(38.7)$ & $71(47.3)$ & 0.02 & $95(45.0)$ & 0.06 \\
\hline Yes & $239(53.1)$ & $68(45.3)$ & $92(61.3)$ & $79(52.7)$ & & $129(54.0)$ & \\
\hline \multicolumn{8}{|c|}{ Sought dental care (last 6 months) } \\
\hline No & $226(50.2)$ & $38(25.3)$ & $60(40.0)$ & $128(85.3)$ & $<0.01$ & & \\
\hline Yes & $224(49.8)$ & $112(74.7)$ & $90(60.0)$ & $22(14.7)$ & & & \\
\hline \multicolumn{8}{|c|}{ Barriers to dental care during pregnancy } \\
\hline Lack of need & $111(24.7)$ & $63(42.0)$ & $30(20.0)$ & $18(12.0)$ & $<0.01$ & $68(61.3)$ & $<0.01$ \\
\hline Fear & $38(8.4)$ & $11(7.3)$ & $13(8.7)$ & $14(9.3)$ & & $15(39.5)$ & \\
\hline $\begin{array}{l}\text { Concern for child's } \\
\text { safety }\end{array}$ & $249(55.3)$ & $61(40.7)$ & $94(62.7)$ & $94(62.7)$ & & $124(49.8)$ & \\
\hline Financial issues & $52(11.6)$ & $15(10.0)$ & $13(8.7)$ & $24(16.0)$ & & $17(32.7)$ & \\
\hline \multicolumn{8}{|c|}{ Advised on seeking dental care } \\
\hline No & $402(89.3)$ & $133(88.7)$ & $136(90.7)$ & $133(88.7)$ & 0.81 & $199(49.5)$ & 0.43 \\
\hline Yes & $48(10.7)$ & $17(11.3)$ & $14(9.3)$ & $17(11.3)$ & & $25(52.1)$ & \\
\hline
\end{tabular}

Dental diseases lead to other medical conditions 
Table 1 Socio-demographic and dental characteristics of the study groups stratified by their pregnancy status and utilization of dental services (Continued)

\begin{tabular}{|c|c|c|c|c|c|c|c|}
\hline \multirow[t]{3}{*}{ Variables } & \multirow{3}{*}{$\begin{array}{l}\text { Total } \\
450 \\
(100.0) \\
\text { N (\%) }\end{array}$} & \multicolumn{3}{|l|}{ Pregnancy Status } & \multirow{3}{*}{$\boldsymbol{P}$ value $^{*}$} & \multirow{2}{*}{$\begin{array}{l}\text { Sought Dental Care (last } 6 \\
\text { months) } \\
\text { Yes }\end{array}$} & \multirow{3}{*}{$\boldsymbol{P}$ value* } \\
\hline & & $\begin{array}{l}\text { Six-month post-partum } \\
\text { women }\end{array}$ & $\begin{array}{l}\text { Pregnant } \\
\text { women }\end{array}$ & $\begin{array}{l}\text { Post-Partum } \\
\text { women }\end{array}$ & & & \\
\hline & & $\begin{array}{l}150(33.3) \\
N(\%)\end{array}$ & $\begin{array}{l}150(33.3) \\
N(\%)\end{array}$ & $\begin{array}{l}150(33.3) \\
N(\%)\end{array}$ & & $\begin{array}{l}224(49.8) \\
N(\%)\end{array}$ & \\
\hline No & $419(93.1)$ & $133(88.7)$ & $136(90.7)$ & $150(100.0)$ & $<0.01$ & $203(48.4)$ & 0.04 \\
\hline Yes & $31(6.9)$ & $17(11.3)$ & $14(9.3)$ & $0(0.0)$ & & $21(67.7)$ & \\
\hline \multicolumn{8}{|c|}{ Bleeding from gums is normal during pregnancy } \\
\hline No & $124(27.6)$ & $41(27.3)$ & $43(28.7)$ & $40(26.7)$ & 0.99 & $61(49.2)$ & 0.48 \\
\hline Yes & $326(72.4)$ & $109(72.7)$ & $107(71.3)$ & $110(73.3)$ & & $163(52.0)$ & \\
\hline \multicolumn{8}{|c|}{ Self-reported oral health status } \\
\hline Good & $43(9.6)$ & $26(17.3)$ & $8(5.3)$ & $9(6.0)$ & $<0.01$ & $26(60.5)$ & $<0.01$ \\
\hline Moderate & $284(63.1)$ & $108(72.0)$ & $96(64.0)$ & $80(53.3)$ & & $151(53.2)$ & \\
\hline Poor & $123(27.3)$ & $16(10.7)$ & $46(30.7)$ & $61(40.7)$ & & $47(38.2)$ & \\
\hline \multicolumn{8}{|c|}{ Self-rating of general health } \\
\hline Good & $58(12.9)$ & $46(30.7)$ & $9(6.0)$ & $3(2.0)$ & $<0.01$ & $39(67.2)$ & $<0.01$ \\
\hline Moderate & $268(59.6)$ & $92(61.3)$ & $98(65.3)$ & $78(52.0)$ & & $135(50.4)$ & \\
\hline Poor & $124(27.6)$ & $12(8.0)$ & $43(28.7)$ & $69(46.0)$ & & $50(40.3)$ & \\
\hline
\end{tabular}

${ }^{*}$ Chi-squared test

groups. Table 1 shows the participants' sociodemographic and dental characteristics stratified by pregnancy status and dental care utilization. About $40 \%$ of the respondents were from Urban areas and about $47 \%$ had completed secondary school education. Most of the participants were unemployed (80.4\%) and belonged to a low income category $(70.2 \%)$. About $50 \%$ of the respondents had sought regular dental care within the previous 6 months.

Religion, education and occupation were significantly different in terms of pregnancy status and dental care utilization. Lower percentage of post-partum women (8.7\%) had graduate or higher level education as compared with pregnant $(28.0 \%)$ or six-month post-partum $(24.7 \%)$ women, which was statistically significant $(p<$ $0.01)$. An increasing trend in the utilization of dental services was observed with an increase in the level of education of the participants $(p<0.01)$. Higher percentage of six-month post-partum women were employed $(36.0 \%)$ as compared with pregnant $(15.3 \%)$ or postpartum $(7.3 \%)$ women $(p<0.01)$. Diet was not significantly associated with dental service utilization, though pregnant women reported to have a higher frequency of consumption of sugary foods $(p<0.01)$. More pregnant women $(66.0 \%)$ reported to have bleeding while brushing as compared with post-partum women $(46.7 \%)$ or sixmonth post-partum $(34.0 \%)$ women, which was statistically significant $(p<0.01)$. Similarly, higher percentage of pregnant women $(61.3 \%)$ reported experiencing dental problems in the last 6 months as compared with post- partum (52.7\%) or six-month post-partum (45.3\%) women $(p=0.02)$. Dental service utilization was significantly higher among women who reported experiencing dental problems $(p=0.06)$. A significant difference in the dental attendance pattern was observed between the study groups $(p<0.01)$. Dental attendance among sixmonth post-partum women and pregnant were about 75 and $60 \%$, respectively, however, only about $15 \%$ of the post-partum women reported to have sought dental care in the 6 months prior to the study. The main barrier to dental care during pregnancy was reported to be 'concern for the safety of the child' followed by 'financial issues' and 'fear of the dentist'. This was again significantly different between pregnant, post-partum and six-month post-partum women, with a higher percentage of pregnant and post-partum women citing 'concern for the child's safety' as the primary barrier to seeking care $(p<0.01)$. Majority of the respondents did not report receiving any advice on the need to seek oral health care during pregnancy. Only about $7 \%$ of the respondents believed that oral disease could lead to other medical conditions. This was significantly different across the groups and also in terms of dental care utilization. About three-fourth of the respondents believed that bleeding from the gums was normal during pregnancy. This was not significantly different between the groups.

A significantly higher percentage of post-partum women reported to have poor oral and general health (40.7 and $46.0 \%$ respectively), as compared to both, 
pregnant and six-month post-partum women $(p<0.01)$. Higher percentage of women reporting 'good' oral and general health had sought dental care compared with others $(p<0.01)$.

Table 2 shows the distribution of the responses to the 4 global dimensions (Knowledge, Function, Quality of life and Social) of self-perceived oral health by pregnant status. The self-rating for all the dimensions were significantly poorer for the post-partum women as compared with pregnant or six-month post-partum women. Total $\mathrm{SPOH}$ scores was significantly different between the three groups (Table 3). Post-partum women had the highest SPOH scores, indicating poor self-perceived oral health, followed by pregnant and then six-month postpartum women, which was statistically significant $(p<0.05)$.

The results of the multivariate logistic regression model to assess the significance of variables as predictors of dental attendance (dental visit in the last 6 months yes/no) are shown in Table 4. Socio-demographic variables were entered in the first step followed by the dental characteristics. In the final step, pregnancy status and $\mathrm{SPOH}$ scores were entered into the model. After adjusting for all the other variables in the model, women with lower levels of education $\left(\mathrm{OR}^{\mathrm{a}}=1.42\right.$; $95 \% \mathrm{CI}$ : $1.01-$ $2.00)$, women with poor self-perceived oral health $\left(\mathrm{OR}^{\mathrm{a}}=\right.$ 1.08; 95\% CI: 1.02-1.14) and post-partum women $\left(\mathrm{OR}^{\mathrm{a}}=0.15\right.$; 95\% CI: $\left.0.09-0.24\right)$ were found to be less likely to seek regular dental care.

\section{Discussion}

This study was carried out in an urban setting at two maternal and child care hospitals in the State of Kerala, India. The selection of these two hospitals were based on the availability of a large number of accessible pregnant, post-partum and six-month post-partum women. These hospitals cater mostly to the low and middle income women and the cost of treatments are subsidized. This study presents the difference in the dental service utilization pattern among low and middle income women at three distinct phases of pregnancy - first trimester, post-partum and six-month post-partum. Postpartum women were least likely to seek routine dental care compared to pregnant or six-month post-partum women.

Pregnancy is associated with higher incidence of oral conditions like gingivitis and periodontitis [4]. The probable reasons for an increase in the risk for dental diseases during pregnancy might be due to inadequate oral hygiene, medical co-morbidities, limited awareness about the importance of maintaining proper oral hygiene and failure to seek regular dental care [5, 6]. Also, maternal oral health is one of the greatest predictors of childhood oral health [23]. Maternal behaviors, including attention to oral hygiene and dietary practice, may also influence this risk.

Pregnant women generally tend to postpone their dental visits until after delivery due to concern over their child's health. In the US, less than $50 \%$ of pregnant women seek dental care during pregnancy [24, 25]. Similarly, other countries such as Australia (36\%), Greece (27\%) and UK (33\%), have reported poor utilization of dental services by pregnant women [26]. Poor utilization of dental services among pregnant women is well documented worldwide and is evident in India as well. In this study, more than half of the respondents reported having experienced some dental problem in the previous 6 months. However, only less than $15 \%$ of the post-partum women sought dental care during the same time period. About threequarter of the six-month post-partum women and more than half of the pregnant women in the first trimester reported seeking dental care within the 6 months prior to the study. This indicates that most women in this study preferred to seek dental care either before the first trimester or postpone it until after delivery. Concern for child's safety is a commonly cited barrier for pregnant women seeking dental care even though it is well established that dental treatment during pregnancy is extremely safe and will not result in adverse pregnancy outcomes [17]. In addition, majority of the participants believe that poor oral health is normal during pregnancy.

Only a tenth of the participants recalled being advised on seeking regular dental care during pregnancy. Oral health is often ignored and not considered as a part of regular antenatal care and this finding is strongly supported by several other studies [17, 27]. Lack of awareness among pregnant women about the importance of maternal oral health is associated with poor utilization of dental services [26]. Only over $5 \%$ of the surveyed women in this study believed that dental diseases could lead to other diseases. Similar findings were reported by Boggess et al. [9].

Most pregnant women in this population undergo at least one antenatal care visit during pregnancy [21]. Doctors and midwives could play a vital role in educating pregnant women and improving their awareness about oral health care during pregnancy. This could also address several misconceptions pregnant women may have, which in turn would influence their oral health practice and potentially improve the uptake of dental services.

Education was associated with dental attendance, with women who had completed secondary or higher education were more likely to seek routine dental care. Similar results were found in a systematic review of 25 studies [28]. Educated women may have better 
Table 2 The 9 questions covering the four global dimensions of self-perceived oral health

\begin{tabular}{|c|c|c|c|c|c|c|}
\hline \multicolumn{7}{|l|}{ Knowledge } \\
\hline & Expert level of Knowledge & Good Knowledge & Fair Knowledge & Some Knowledge & No Knowledge & $P$ value* \\
\hline \multicolumn{7}{|c|}{ Q 1. Do you know the mechanism behind caries and periodontal diseases? } \\
\hline Six-month post-partum women & $11(7.3)$ & $30(20.0)$ & $9(6.0)$ & $32(21.3)$ & $68(45.3)$ & \multirow[t]{3}{*}{$<0.01$} \\
\hline Pregnant & $1(0.7)$ & $5(3.3)$ & $28(18.7)$ & $54(36.0)$ & $62(41.3)$ & \\
\hline Post-Partum & $3(2.0)$ & $18(12.0)$ & $26(17.3)$ & $55(36.7)$ & $48(32.0)$ & \\
\hline \multicolumn{7}{|c|}{ Q 2. Do you know how to avoid caries and periodontal diseases? } \\
\hline Six-month post-partum women & $7(4.7)$ & $29(19.3)$ & $8(5.3)$ & $37(24.7)$ & $69(46.0)$ & \multirow[t]{3}{*}{$<0.01$} \\
\hline Pregnant & $0(0.0)$ & $2(1.3)$ & $21(14.0)$ & $68(45.3)$ & $59(39.3)$ & \\
\hline Post-Partum & $2(1.3)$ & $18(12.0)$ & $44(29.3)$ & $57(38.0)$ & $29(19.3)$ & \\
\hline \multicolumn{7}{|c|}{ Q 3. Do you know that it is important to use fluoridated toothpaste? } \\
\hline Six-month post-partum women & $12(8.0)$ & $57(38.0)$ & $39(26.0)$ & $40(26.7)$ & $2(1.3)$ & \multirow[t]{3}{*}{$<0.01$} \\
\hline Pregnant & $10(6.7)$ & $23(15.3)$ & $48(32.0)$ & $47(31.3)$ & $22(14.7)$ & \\
\hline Post-Partum & $15(10.0)$ & $38(25.3)$ & $39(26.0)$ & $30(20.0)$ & $28(18.7)$ & \\
\hline \multicolumn{7}{|l|}{ Function } \\
\hline & Never & Hardly Ever & Occasionally & Fairly Often & Very Often & \\
\hline \multicolumn{7}{|c|}{ Q 4. You feel severe pain while drinking hot or cold drinks } \\
\hline Six-month post-partum women & $14(9.3)$ & $31(20.7)$ & $78(52.0)$ & $22(14.7)$ & $5(3.3)$ & \multirow[t]{3}{*}{$<0.01$} \\
\hline Pregnant & $1(0.7)$ & $6(4.0)$ & $35(23.3)$ & $59(39.3)$ & $49(32.7)$ & \\
\hline Post-Partum & $1(0.7)$ & $1(0.7)$ & $23(15.3)$ & $70(46.7)$ & $55(36.7)$ & \\
\hline \multicolumn{7}{|c|}{ Q 5. You have headaches due to your teeth or your mouth } \\
\hline Six-month post-partum women & $38(25.3)$ & $57(38.0)$ & $44(29.3)$ & $10(6.7)$ & $1(0.7)$ & \multirow[t]{3}{*}{$<0.01$} \\
\hline Pregnant & $14(9.3)$ & $34(22.7)$ & $57(38.0)$ & $29(19.3)$ & $16(10.7)$ & \\
\hline Post-Partum & $3(2.0)$ & $20(13.3)$ & $40(26.7)$ & $56(37.3)$ & $31(20.7)$ & \\
\hline \multicolumn{7}{|l|}{ Q 6. You have difficulty eating food } \\
\hline Six-month post-partum women & $57(38.0)$ & $56(37.3)$ & $29(19.3)$ & $8(5.3)$ & $0(0.0)$ & \multirow[t]{3}{*}{$<0.01$} \\
\hline Pregnant & $18(12.0)$ & $34(22.7)$ & $42(28.0)$ & $33(22.0)$ & $23(15.3)$ & \\
\hline Post-Partum & $11(7.3)$ & $17(11.3)$ & $33(22.0)$ & $49(32.7)$ & $40(26.7)$ & \\
\hline \multicolumn{7}{|l|}{ Quality of Life } \\
\hline \multicolumn{7}{|c|}{ Q 7. You feel depressed due to your teeth or your mouth } \\
\hline Six-month post-partum women & $51(34.0)$ & $61(40.7)$ & $32(21.3)$ & $6(4.0)$ & $0(0.0)$ & \multirow[t]{3}{*}{$<0.01$} \\
\hline Pregnant & $12(8.0)$ & $52(34.7)$ & $55(36.7)$ & $29(19.3)$ & $2(1.3)$ & \\
\hline Post-Partum & $6(4.0)$ & $38(25.3)$ & $32(21.3)$ & $46(30.7)$ & $28(18.7)$ & \\
\hline \multicolumn{7}{|l|}{ Social } \\
\hline \multicolumn{7}{|c|}{ Q 8. You avoid laughing due to your teeth or your mouth } \\
\hline Six-month post-partum women & $37(24.7)$ & $47(31.3)$ & $50(33.3)$ & $15(10.0)$ & $1(0.7)$ & \multirow[t]{3}{*}{$<0.01$} \\
\hline Pregnant & $3(2.0)$ & $25(16.7)$ & $45(30.0)$ & $43(28.7)$ & $34(22.7)$ & \\
\hline Post-Partum & $1(0.7)$ & $12(8.0)$ & $40(26.7)$ & $58(38.7)$ & $39(26.0)$ & \\
\hline \multicolumn{7}{|c|}{ Q 9. You feel embarrassed due to your teeth or your mouth } \\
\hline Six-month post-partum women & $53(35.3)$ & $53(35.3)$ & $34(22.7)$ & $10(6.7)$ & $0(0.0)$ & \multirow[t]{3}{*}{$<0.01$} \\
\hline Pregnant & $7(4.7)$ & $41(27.3)$ & $45(30.0)$ & $32(21.3)$ & $25(16.7)$ & \\
\hline Post-Partum & $5(3.3)$ & $21(14.0)$ & $33(22.0)$ & $61(40.7)$ & $30(20.0)$ & \\
\hline
\end{tabular}

*Chi-squared test

knowledge and awareness about the importance of oral health and regular dental visits especially during pregnancy. Also, educated women might have better health literacy, therefore they might be able to navigate the healthcare system better [29]. Similarly, more working women sought routine dental care as compared with unemployed women. Cost of dental services is a significant barrier especially among those belonging to the low socio-economic strata and those with minimal household incomes [26]. 
Table 3 Total self-perceived oral health score

\begin{tabular}{llll}
\hline Total SPOH scores & Mean & SD & $\boldsymbol{P}$ Value* \\
\hline Six-month post-partum women & 12.43 & 4.29 & $<0.05 \dagger \S$ \\
Pregnant & 22.16 & 5.05 & $<0.05 \S ¥$ \\
Post-Partum & 23.74 & 3.37 & $<0.05 \dagger ¥$
\end{tabular}

*Analysis of variance (ANOVA) with Tukey's post-hoc multiple comparisons † As compared with pregnant women; § As compared with post-partum women; $¥$ As compared with six-month post-partum women

In the multivariate model, self-perceived oral health scores were associated with dental service utilization. It should be noted that the four self-reported global dimensions measure problems with mouth and teeth in general and were not restricted to the social and psychological consequences resulting from any particular dental pathology. Differences in the self-perceived oral health between the different groups of women reflect not only the variations in oral conditions but also variations in their attitudes towards oral health.

As described by Andersen [12], health services work towards improving the health status of the population, both as perceived by the population and as evaluated by health care professionals. The Andersen model acknowledges the role of several environmental and population characteristics in determining the need for oral health care, which could be perceived or normative. Though several studies have assessed the normative need of pregnant women, only few studies have explored the intricate relationship between perceived need and utilization of dental services. It is important to understand perceived need as it is closely related to the concept of self-efficacy. Self-efficacy assumes that people adopt self-care practices if they perceive that these practices make a difference [30]. While several programs focus on educating and motivating pregnant women on the importance of good oral hygiene, the role of selfperceived oral health need is often overlooked. This study shows that self-perceived oral health is strongly associated with dental utilization. Therefore, raising the awareness towards oral health among pregnant women

Table 4 Summary of Multivariate logistic regression analysis with dental visit within previous 6 months (yes/no) as the dependent variable

\begin{tabular}{lllll}
\hline Independent variables & $\mathrm{B}$ & $\mathrm{SE}$ & $\mathrm{OR}$ & 95\% Confidence Interval \\
\hline Place of residence & 0.29 & 0.27 & 1.34 & $0.78-2.28$ \\
Religion & 0.20 & 0.18 & 1.22 & $0.86-1.74$ \\
Occupation & 0.41 & 0.36 & 1.5 & $0.74-3.06$ \\
Education & 0.35 & 0.18 & 1.42 & $1.01-2.00$ \\
Socio-Economic Status & 0.51 & 0.28 & 1.66 & $0.96-2.90$ \\
Pregnancy Status & -1.92 & 0.24 & 0.15 & $0.09-0.24$ \\
SPOH score & 0.07 & 0.03 & 1.08 & $1.02-1.14$ \\
\hline
\end{tabular}

Nagelkerke R Square $=40.7 \%$ might lead to behavior changes that could improve dental utilization during pregnancy. Poor oral health during pregnancy can be detrimental to the mothers' health and also to the well-being of the baby.

This study describes the plausible role of pregnancy status, educational level and self-perceived oral health in the utilization of dental services. Though the study was pragmatic and carried out in a non-research setting, it managed to get an acceptable response rate from the population studied. However, the results of this study should be interpreted with caution. Since this is a crosssectional study, the direction of the causal relationship cannot be resolved. It is recognized that several pregnancy-related factors could lead women to perceive their oral health more negatively. It is also understood that dental service utilization is a complex interplay of several factors including availability, accessibility, social and cultural belief's and finance. Further, additional assessments of pain, halitosis or esthetics were not performed in this study, which may influence the overall oral health perception. More robust longitudinal studies are required to explore the different variables contributing to dental service utilization.

\section{Conclusions}

Pattern of dental service utilization among women in this population varied according to their pregnancy status, level of education and self-perceived oral health. Inclusion of an oral health component to the routine antenatal care in this population may improve awareness regarding the importance of oral health among vulnerable pregnant women.

\section{Abbreviations}

NFHS: National family health survey; SPOH: Self perceived oral health; SES: Socio-economic status; SLI: Standard of living index

\section{Acknowledgements}

The authors thank all the women who participated in this study.

\section{Authors' contributions}

JKB designed the study, analyzed the data and was a major contributor in writing the manuscript. AG helped in interpretation of the data and in editing the manuscript. Both the authors have read and approved the final manuscript.

\section{Funding}

This study did not receive financial support from any sources. The authors would like to the thank Kuwait University Research Sector for funding the article-processing charges of this publication.

\section{Availability of data and materials \\ The datasets analysed in the current study are available from the} corresponding author on reasonable request.

\section{Ethics approval and consent to participate}

This research was conducted in accordance with the World Medical Association Declaration of Helsinki and approved by the Institutional Review Board (IRB) of Sree Chitra Tirunal Institute of Medical Sciences and

Technology. Permission to conduct the study at the two hospitals were obtained from the concerned authorities. All participants provided written informed consent. 


\section{Consent for publication}

Not Applicable.

\section{Competing interests}

The authors declare that they have no competing interests.

\section{Author details}

'Division of Dental Public Health, Department of Developmental and Preventive Sciences, Faculty of Dentistry, Kuwait University, 13110 Kuwait City, Kuwait. ${ }^{2}$ Resident, Dental Public Health, Department of Preventive and Restorative Dental Sciences, School of Dentistry, University of California San Francisco, 707 Parnassus Avenue, San Francisco, CA 94143, USA

Received: 2 May 2019 Accepted: 11 March 2020

Published online: 20 April 2020

\section{References}

1. Bloch M, Daly RC, Rubinow DR. Endocrine factors in the etiology of postpartum depression. Compr Psychiatry. 2003;44(3):234-46.

2. Mascarenhas P, Gapski R, Al-Shammari K, Wang HL. Influence of sex hormones on the periodontium. J Clin Periodontol. 2003;30(8):671-81.

3. Offenbacher S, Katz V, Fertik G, Collins J, Boyd D, Maynor G, McKaig R, Beck J. Periodontal infection as a possible risk factor for preterm low birth weight. J Periodontol. 1996;67(10 Suppl):1103-13.

4. Baskaradoss JK, Geevarghese A, Al Dosari AA. Causes of adverse pregnancy outcomes and the role of maternal periodontal status - a review of the literature. Open Dent J. 2012;6:79-84.

5. Baskaradoss JK, Geevarghese A, Kutty VR. Maternal periodontal status and preterm delivery: a hospital based case-control study. J Periodontal Res. 2011:46(5):542-9.

6. Lieff S, Boggess KA, Murtha AP, Jared H, Madianos PN, Moss K, Beck J, Offenbacher $\mathrm{S}$. The Oral conditions and pregnancy study: periodontal status of a cohort of pregnant women. J Periodontol. 2004;75(1):116-26.

7. Geevarghese A, Baskaradoss JK, Sarma PS. Oral health-related quality of life and periodontal status of pregnant women. Matern Child Health J. 2017; 21(8):1634-42.

8. Machuca G, Khoshfeiz O, Lacalle JR, Machuca C, Bullon P. The influence of general health and socio-cultural variables on the periodontal condition of pregnant women. J Periodontol. 1999;70(7):779-85.

9. Boggess KA, Urlaub DM, Moos M-K, Polinkovsky M, El-Khorazaty J, Lorenz C. Knowledge and beliefs regarding oral health among pregnant women. J Am Dent Assoc. 2011;142(11):1275-82.

10. De Oliveira CM, Sheiham A. The relationship between normative orthodontic treatment need and oral health-related quality of life. Community Dent Oral Epidemiol. 2003:31(6):426-36.

11. Åstrøm AN, Kida IA. Perceived dental treatment need among older Tanzanian adults-a cross-sectional study. BMC Oral Health. 2007:7(1):9.

12. Andersen RM. Revisiting the behavioral model and access to medical care: does it matter? J Health Soc Behav. 1995:36(1):1-10.

13. Michalowicz BS, DiAngelis AJ, Novak MJ, Buchanan W, Papapanou PN, Mitchell DA, Curran AE, Lupo VR, Ferguson JE, Bofill J. Examining the safety of dental treatment in pregnant women. J Am Dent Assoc. 2008;139(6):685-95.

14. Corbella S, Taschieri S, Francetti L, De Siena F, Del Fabbro M. Periodontal disease as a risk factor for adverse pregnancy outcomes: a systematic review and meta-analysis of case-control studies. Odontology. 2012;100(2): 232-40.

15. Ide M, Papapanou PN. Epidemiology of association between maternal periodontal disease and adverse pregnancy outcomes--systematic review. J Clin Periodontol. 2013;40(Suppl 14):S181-94.

16. Obstetricians ACO, Gynecologists. Oral health care during pregnancy and through the life span. Committee opinion no. 569. Obstet Gynecol. 2013; 122(2):417-22

17. George A, Johnson M, Blinkhorn A, Ajwani S, Bhole S, Yeo A, Ellis S. The oral health status, practices and knowledge of pregnant women in SouthWestern Sydney. Aust Dent J. 2013;58(1):26-33.

18. Al Habashneh R, Guthmiller JM, Levy S, Johnson GK, Squier C, Dawson DV, Fang Q. Factors related to utilization of dental services during pregnancy. J Clin Periodontol. 2005;32(7):815-21.

19. Kloetzel MK, Huebner CE, Milgrom P. Referrals for dental care during pregnancy. J Midwifery Womens Health. 2011;56(2):110-7.
20. von Elm E, Altman DG, Egger M, Pocock SJ, Gotzsche PC, Vandenbroucke $J P$, Initiative $S$. The strengthening the reporting of observational studies in epidemiology (STROBE) statement: guidelines for reporting observational studies. Int J Surg. 2014;12(12):1495-9.

21. International Institute for Population Sciences (IIPS) and University of Kerala: National Family Health Survey (NFHS-2), India, 1998-99: Kerala. Bombay 2001.

22. Ekback G, Astrom AN, Klock K, Ordell S, Unell L. Self-perceived oral health among 19-year-olds in two Swedish counties. Swed Dent J. 2008;32(2):83-93.

23. Weintraub JA, Prakash P, Shain SG, Laccabue M, Gansky SA. Mothers' caries increases odds of children's caries. J Dent Res. 2010;89(9):954-8.

24. Lydon-Rochelle MT, Krakowiak P, Hujoel PP, Peters RM. Dental care use and self-reported dental problems in relation to pregnancy. Am J Public Health. 2004;94(5):765-71.

25. Gaffield ML, Gilbert BJ, Malvitz DM, Romaguera R. Oral health during pregnancy: an analysis of information collected by the pregnancy risk assessment monitoring system. J Am Dent Assoc. 2001;132(7):1009-16.

26. Keirse MJ, Plutzer K. Women's attitudes to and perceptions of oral health and dental care during pregnancy. J Perinat Med. 2010;38(1):3-8.

27. George A, Johnson M, Blinkhorn A, Ellis S, Bhole S, Ajwani S. Promoting oral health during pregnancy: current evidence and implications for Australian midwives. J Clin Nurs. 2010;19(23-24):3324-33.

28. Xiong $X$, Buekens $P$, Fraser WD, Beck J, Offenbacher S. Periodontal disease and adverse pregnancy outcomes: a systematic review. BJOG. 2006;113(2): 135-43.

29. Baskaradoss JK. The association between oral health literacy and missed dental appointments. J Am Dent Assoc. 2016;147(11):867-74.

30. Bandura A. Self-efficacy: toward a unifying theory of behavioral change. Psychol Rev. 1977:84(2):191-215.

\section{Publisher's Note}

Springer Nature remains neutral with regard to jurisdictional claims in published maps and institutional affiliations.

\section{Ready to submit your research? Choose BMC and benefit from:}

- fast, convenient online submission

- thorough peer review by experienced researchers in your field

- rapid publication on acceptance

- support for research data, including large and complex data types

- gold Open Access which fosters wider collaboration and increased citations

- maximum visibility for your research: over $100 \mathrm{M}$ website views per year

At BMC, research is always in progress.

Learn more biomedcentral.com/submissions 